\title{
ESTUDO LEXICAL DE UM PROCESSO CRIME DE ESTUPRO DO INÍCIO DO SÉCULO XX
}

\author{
Claudice Ferreira Santos ${ }^{1}$; Rita de Cássia Ribeiro de Queiroz ${ }^{2}$ \\ 1. Bolsista PROBIC/UEFS, Graduanda em Licenciatura em Letras Vernáculas, Universidade Estadual de Feira de \\ Santana, e-mail: claudicekau@ hotmail.com \\ 2. Orientador, Departamento de Letras e Artes, Universidade Estadual de Feira de Santana, e-mail: \\ rcrqueiroz@uol.com.br
}

\section{INTRODUÇÃO}

PALAVRAS-CHAVE: Léxico; Sexualidade; Campos lexicais.

O léxico é considerado um patrimônio vocabular de uma determinada comunidade linguística. Segundo Biderman (1981, p. 138), o léxico é o “[...] tesouro vocabular de uma determinada língua [...]", que incorpora a "[...] nomenclatura de todos os conceitos lingüísticos e não-lingüísticos e de todos os referentes do mundo físico e do universo cultural, criado por todas as culturas humanas atuais e do passado". Portanto, o léxico é o nível da língua com melhor destaque da realidade extralinguística, pois estudar a língua em seu uso contextual pode reconstruir a sociedade a partir do inventário do léxico, de modo que estudar o léxico também é estudar a história, a memória e a cultura de um povo.

O léxico transita entre a gramática e a literatura, é um acervo de palavras e de conhecimento de um determinado idioma que existe na consciência dos falantes. Neste sentido, destacamos a definição de léxico como o "[...] saber partilhado que existe na consciência dos falantes de uma língua, constitui-se no acervo do saber vocabular de um grupo sociolinguístico-cultural" (OLIVEIRA; ISQUERDO, 1998, p.7).

Nesse sentido, a todo o momento estamos fazendo uso do léxico. A comunicação é um dos principais quesitos para o processo de nomeação que, por sua vez, é o processo pelo qual expressamos e representamos os nossos pensamentos e sensações por meio de palavras. O léxico vai se materializando com os rótulos, a partir do momento novas palavras surgem e os rótulos se materializam.

Durante o desenvolvimento desta pesquisa, foi realizado o estudo do léxico de um documento do início do século XX, especificamente um processo crime de estupro de 1911. Objetivamos, no presente trabalho, apresentar as diversas lexias do campo semântico da sexualidade, encontradas no processo crime de estupro. Portanto, a partir do levantamento das lexias, foi realizado o estudo do léxico, o qual será apresentado a seguir.

\section{MATERIAL E MÉTODOS OU METODOLOGIA (ou equivalente)}

Processo crime de estupro do início do século XX.

Método de análise é o da lexicologia, através da teoria dos campos lexicais postulada por Eugenio Coseriu ([1977] 1986).

\section{RESULTADOS E/OU DISCUSSÃO (ou Análise e discussão dos resultados)}

Após a leitura de algumas referências no cerne dos campos lexicais, ciências do léxico, dentre outros, foi feito o levantamento das lexias correspondentes ao campo semântico da sexualidade. 


\section{CAMPO LEXICAL DA SEXUALIDADE}

1.1 Macrocampo: Órgãos Sexuais

\subsubsection{PARTES DA OFENDIDA}

CARÚNCULAS - s. f proeminência carnosa, avermelhada, que existe de modo normal ou patológica, em diversas partes do corpo.

"[...] a membrana hymen toda reta mais ja cicatrizada, aparentando as carúnculas aspecto multiformas." (f. 11r,1. 11- 3)

CLITÓRIS - s. m pequeno órgão erétil do aparelho genital feminino, situado na porção mais anterior da vulva, que se projeta entre os pequenos lábios, e é composto de uma glande, um corpo e dois pedúnculos.

"[...] o clytories, o vestibulo digo". (f. 11r, 1. 4-5)

CONDUCTO VULVO VAGINAL - algo que serve para conduzir, dar passagem levar algo de um lugar para outro; duto carnal.

"[...] comducto vulvo vaginal e a embocadura". (f. 11r, 1. 10)

PARTES GENITAIS EXTERNAS - loc. subst. 'Lábios vaginais'.

"[...] partes genitaes externas, e nem internas, nem nas coxas.” (f. 11r, 1. 24-25)

PARTES GENITAIS INTERNAS - loc. subst. 'Lábios vaginais'.

"[...] partes genitaes externas, e nem internas, nem nas coxas." (f. 11r, 1. 24-25)

COXAS - s.f. ANAT parte do membro inferior entre o quadril e o joelho.

"partes genitaes externas, e nem internas, nem nas coxas." (f. 11R, 1. 24-25)

EMBOCADURA DAS GLÂNDULAS - s. f ato ou efeito de embocar.

"[...] comducto vulvo vaginal e a emboccadura das glândulas." (f. 11r, 1. 10-11)

FURCULA - extremidade da vagina.

“A FURCULA apresenta-se um pouco acchymozada.” (f. 11R, 1. 7-8)

PARTES GENITAIS - loc. subst. 'Lábios vaginais'.

“[...] não sentia dor alguma nas partes genitaes externas.”(f. 10v, 1. 23-24)

HYMEN - s.m. 'Prega formada pela membrana mucosa e que fecha parcialmente o orifício da vagina virginal'.

“A membrana hymen está toda reta mais ja cicatrizada." (f. 11r, 1. 1-2)

GRANDES LABIOS - dobras de pele existente na vulva.

“[...] apresentão os grandes labios pouco separados" (f. 10v, 1. 31-32)

MECTO URINÁRIO - abertura, extremidade da uretra meato por onde sai a urina, se encontra entre o clitóris e o meato.

“[...] digo vestibulo e o mecto urinario não apresentão nada desanormal. (f. 11r, 1. 15-7) 
MEMBRANA HYMEN - s.m. 'Prega formada pela membrana mucosa e que fecha parcialmente o orifício da vagina virginal. Hímem.'

“[...]A membrana hymen está toda reta mais ja cicatrizada.” (f. 11r, 1. 1-2)

ORIFICIO DA VAGINA - loc. Subst.. canal que se estende do colo do útero à vulva. “[...]o orificio da vagina,[...]" (f. 11r, 1. 19)

VESTÍBULO - porção da vulva que é limitada em cima pelo clitóris em baixo pelo orifício da uretra e aos lados pelos pequenos lábios.

“[...]o clytories, o vestibulo digo vestíbulo." (f. 11r, 1. 19-10)

SEIOS - anat m.q. MAMA

"[...]nem nos seios e que havia sido deflorada [...]" (f. 10v, 1. 26-27)

\subsubsection{PARTES DO OFENSOR}

MEMBRO VERIL - loc. adj. 'Órgão genital masculino'. $\rightarrow$ 'Órgão copulador masculino'. $\rightarrow$ 'Pênis'.

"[...]que houve introdução de membro viril ou de um corpo qualquer." (f. 11r, 1. 2425)

\subsection{DAS AÇOES}

ABUZADO - v.t.d. 'Desvirginar'

"Perguntado porque motivo Joaquim depois de haver abuzado da honra da alludida menor." (f. 19 r, 1.6 - 9)

DEFLORADA- v.t.d. 'Desvirginar'. $\rightarrow$ Forçar ao coito usando violência'.

"[...] e que havia sido deflorada (f. 10v, 1. 27)

DESONRAR - v.t.d. "desvirginar'. ' Levar a mulher a perder a virgindade antes do casamento.

“[...] do Tanquinho que devia ou era autor da desonra de Martina, e que esta so se queixa de Joaquim. (f. 29v, 1. 20 - 23)

ESTUPRAR - v.t.d. 'forçar (alguém) a ter relações sexuais, usando de violência física; violar, violentar

"[...] a reparar, pelo vinculo indissolúvel do casamento, o delicto que desejava por em pratica, consegue estuprar a infeliz (f. 2r, 1. 30-32)

\subsection{COMPORTAMENTOS SEXUAIS}

GALANTEIOS - S.m ato ou efeito de galantear; ato ou dito galante; atenção amorosa. "[...] isto devido aos galanteios do mesmo joaquim," (f. $9 \mathrm{v}, 1.2-3$ )

INSTINCTOS BESTEAES - loc. adj. 'desejos sexuais'

"[...] aos seus instinctos besteaes,.” (f. 2r, 1. 26)

FIM LIBIDINOSO - loc. adj. 'desejo sexual'

"[...] para fim libidinozo;" (f. 10v, 1. 3-4)

MEIOS SEDUCTORES - loc. adj. 'desejo sexual' 
"[...] em alli chegando, o denunciado, pelos meios seductores de um galanteio audaz." (f. 2r, 1. 25-26)

SEDUZIO - v.t.d. 'Desonrar, recorrendo a promessas, encantos ou amavios'. $\rightarrow$ 'Conduzir ao ato sexual'.

"[...] fazendo-lhe mil propostas de cazamento a seduzio." (f. 9v, 1. 19-20)

COPULA CARNAL - loc. adj. 'Ato sexual'. $\rightarrow$ 'Coito'.

"Qual o meio empregado; Se houve copula carnal;" (f. 10 v, 1. 1- 2)

\subsection{DOS QUALIFICADORES}

OFENDIDA - adj. 'desvirginada'

"[...] e que endagando a sua filha esta lhe confessara que acabava de ter offendida na sua honra." (f. $14 \mathrm{v}, 1.11-14$ )

DEFLORADA - adj. 'desvirginada'

"[...] e que havia sido deflorada." (f. 10v, 1. 27)

\subsection{DAS CONDIÇÕES FISICAS}

ECCHYMOZADA - mancha escura ou azulada devido a infiltração desusa de sangue no tecido subcutânea.

“[...] A furcula a presenta-se um pouco ecchymozada." (f. $11 \mathrm{r}, 1.7$ - 8)

CICATRIZADA - que se curou, que se fechou por cicatriz.

"[...] A membrana hymen toda reta mais ja cicatrizada." (f. 11r, 1. 1-2)

\section{CONSIDERAÇÕES FINAIS}

Diante da importância dos estudos lexicais, os quais nos fazem trilhar pelos caminhos da história da humanidade, suas relações com o meio, com o outro e consigo mesma, empreendemos a pesquisa sobre o campo lexical da sexualidade a partir da edição de um processo de estupro lavrado em 1911. Com isso, esperamos contribuir para o avanço dos estudos lexicais e linguísticos.

\section{REFERÊNCIAS}

ABBADE, C. M. de S. 2006. O estudo do léxico. In: TEIXEIRA, M. da C. R.; QUEIROZ, R. de C. R. de; SANTOS, R. B. dos (Org.). Diferentes perspectivas dos estudos filológicos. Salvador: Quarteto. p. 213-225.

BIDERMAN, M. T. 1981. A estrutura mental do léxico. In: Estudos de filologia e lingüística. Homenagem a Isaac Nicolau Salum. São Paulo: T.A. Queiroz / Edusp. p.131-145.

COSERIU, E. 1977. Princípios de semântica estructural. Vers. esp. de Marcos Martinez Hernández, rev. por el autor. Madrid: Gredos.

OLIVEIRA, A. M. P. P. de; ISQUERDO, A. N. (Org.). 1998. As ciências do léxico: lexicologia, lexicografia, terminologia. Campo Grande-MS: Ed. UFMS.

QUEIROZ, R. de C. R. de (Org.). 2009. Língua, cultura e sociedade: estudos sobre o léxico. Feira de Santana: Universidade Estadual de Feira de Santana. 1 CD. 